\title{
Editorial: Pedagogic frailty and concept mapping
}

Ian M. Kinchin

University of Surrey, Guildford, UK

Paulo R. M. Correia

Universidade de São Paulo, SP, Brazil

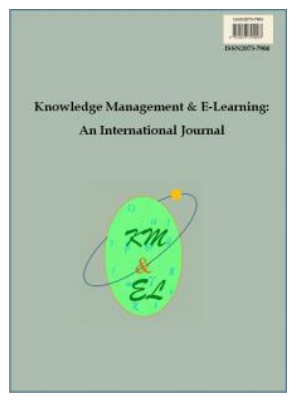

Knowledge Management \& E-Learning: An International Journal (KM\&EL) ISSN 2073-7904

\section{Recommended citation:}

Kinchin, I. M., \& Correia, P. R. M. (2017). Editorial: Pedagogic frailty and concept mapping. Knowledge Management \& E-Learning, 9(3), 254260 . 


\title{
Editorial: Pedagogic frailty and concept mapping
}

\author{
Ian M. Kinchin* \\ Department of Higher Education \\ University of Surrey, Guildford, UK \\ E-mail: i.kinchin@surrey.ac.uk
}

\section{Paulo R. M. Correia}

Escola de Artes, Ciências e Humanidades

Universidade de São Paulo, SP, Brazil

E-mail: prmc@usp.br

*Corresponding author

\begin{abstract}
The model of pedagogic frailty adds cohesion to consideration of the factors that impinge upon teaching at university and which may inhibit innovation. The model was developed through the examination of expert knowledge structures using concept maps. In this editorial, we summarise the pedagogic frailty model and explain its relationship to the concept mapping tool. We emphasise the need to use excellent concept maps (succinct maps with high explanatory power) for the development of theory and the exploration of the 'yet-to-be-known'. We introduce the papers in this special issue that each consider pedagogic frailty and/or concept mapping from different perspectives. This illustrates the utility of the frailty model and how it connects to a variety of well-established bodies of research that influence activities within universities at all levels.
\end{abstract}

Keywords: Adaptive expertise; Resilience; Excellent concept maps; Professional values; Academic development; Knowledge structures

Biographical notes: Ian Kinchin is Professor of Higher Education in the Department of Higher Education at the University of Surrey, UK. He is actively engaged in research to enhance the application of concept mapping to improve the quality of teaching at university. His current focus is on the exploration of the pedagogic frailty model as a tool to support faculty development. He is the editor of the Journal of Biological Education and is a member of the Governing Council of the Society for Research into Higher Education.

Paulo Correia is Professor within the School of Arts, Science and Humanities at the University of São Paulo. He has been involved in research on concept mapping applied to teaching and learning since 2006. His current research aims to understand how to optimize the use of concept mapping in considering human cognitive architecture. Paulo was the chairman of the Sixth International Conference on Concept Mapping (CMC2014) organized by USP and IHMC. 


\section{Pedagogic frailty}

Academics who teach at university are embedded in a complex professional environment in which the potential for stress is high. In order to provide a greater sense of coherence to our appreciation of the teaching role and to help manage that stress, the model of pedagogic frailty has been developed to visualise the factors that jostle for position in our workplace. Where these dimensions are in tension with each other across the campus, an environment of pedagogic frailty will be observed to exist in which conservative, possibly out-dated, teaching practices are preserved. Where frailty can be managed and replaced by resilience, the outcome for the institution (and for the individuals within that institution) is likely to be greater levels of innovation and the development of greater adaptive expertise - rather than routinization of practice.

The overall model of pedagogic frailty is summarised in Fig. 1. The concept is composed of four connected dimensions:

- Regulative Discourse : referring to discussions about the theories, values and beliefs that underpin teaching, rather than the more ephemeral discussions about the mechanisms of teaching (staffing, timetabling etc.) that tend to dominate discussions with a short-term focus.

- Pedagogy \& Discipline: referring to the ways in which the discipline is practiced and how that is reflected in the way it is taught. Colleagues often talk about 'authenticity' in the way in which a subject is taught and may link theory and practice, or education and employability.

- Research-Teaching Nexus: refers to the ways in which teaching and research may be able to inform each other. Perceptions of this relationship vary tremendously among academics, depending in part on whether research is seen as a product or as a process and the relative importance of teaching and research to their professional identity.

- Locus of Control: refers to the point where rules and regulations about teaching are formulated and implemented. This can be concentrated within a centralised management team, or more distributed among the experts that compose the academic community. In addition, external professional bodies may also regulate teaching practices, and can create tensions with institutional policies.

\section{Concept mapping}

The concept of pedagogic frailty 'came into view' as part of a wider exploration of a knowledge structures perspective on teaching and learning at university, facilitated by the application of concept mapping (Kinchin, 2016). The initial visualisation of the pedagogic frailty model was therefore dependent upon the use of concept maps, and it was essential that the concept maps that guided the evolution of this model were of the highest possible quality in order to yield rich and informative data (Fig. 2). Within the current work on pedagogic frailty (e.g. Kinchin et al., 2016; Kinchin \& Francis, 2017) those who have been interviewed are subject experts but novice concept mappers. The point of this work was not to develop the interviewees' concept mapping skills, but produce concise, explanatory concept maps that would represent their perceptions of the dimensions within the frailty model. If the interviewees are left to produce maps on their own, experience has shown that they are likely to produce extensive maps (to include everything that might be of interest) and use simple linking phrases to join the concepts together. However, by employing map-mediated interviews where the interviewer is an 
experienced concept mapper, the process is able to guide the interviewee to produce better quality concept maps (often smaller, but with highly explanatory linking phrases). It has to be remembered that the map has the function of highlighting connections and prompting dialogue. The map is the artefact that colleagues will use as a prompt or a frame to develop their own professional narrative about their teaching. As the academic may be constructing his/her narrative over a period of months after the initial interview, it is crucial that the map is clear and concise with high explanatory power, and is not cluttered by a lot of unnecessary material that may obscure the main ideas.

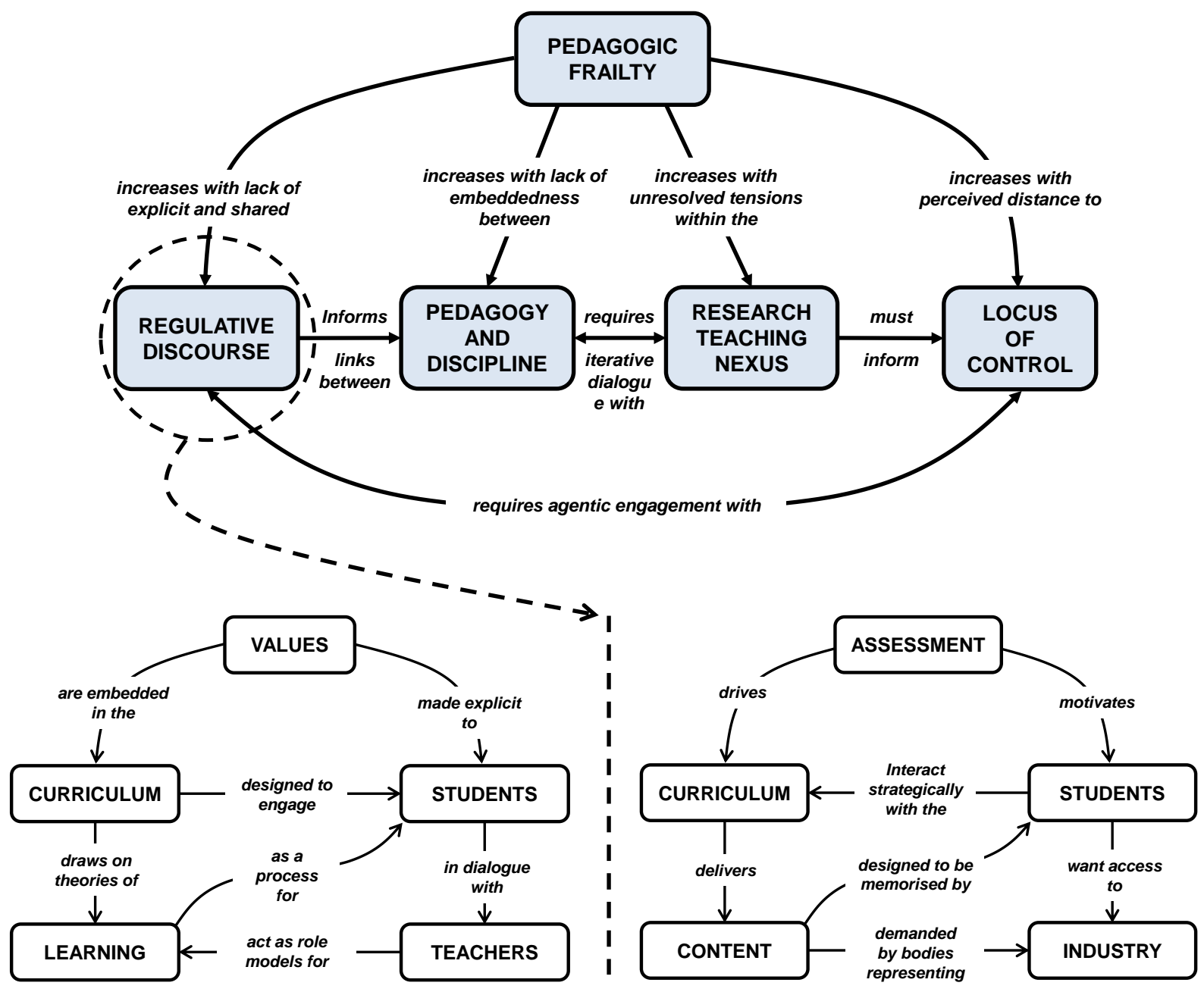

Fig. 1. The overall pedagogic frailty model (above) with (inset below) two academics' contrasting views of the regulative discourse dimension (adapted from Kinchin, 2015; 2016). The maps of regulative discourse show that views can be held by colleagues that are very different to each other and may be in opposition.

Concept maps of each dimension reveal the underlying beliefs of academics that might be obscured by the widespread use of accepted terms such as 'teaching excellence' or 'research-led teaching'. Where these terms have contested meanings they may mask differences in understanding. Such differences may lead to pedagogic frailty, especially 
where they are buried under false assumptions about agreed meanings. The act of mapping not only makes these views available for discussion, but also facilitates personal reflection - allowing individuals to examine and reflect upon their own beliefs and assumptions.

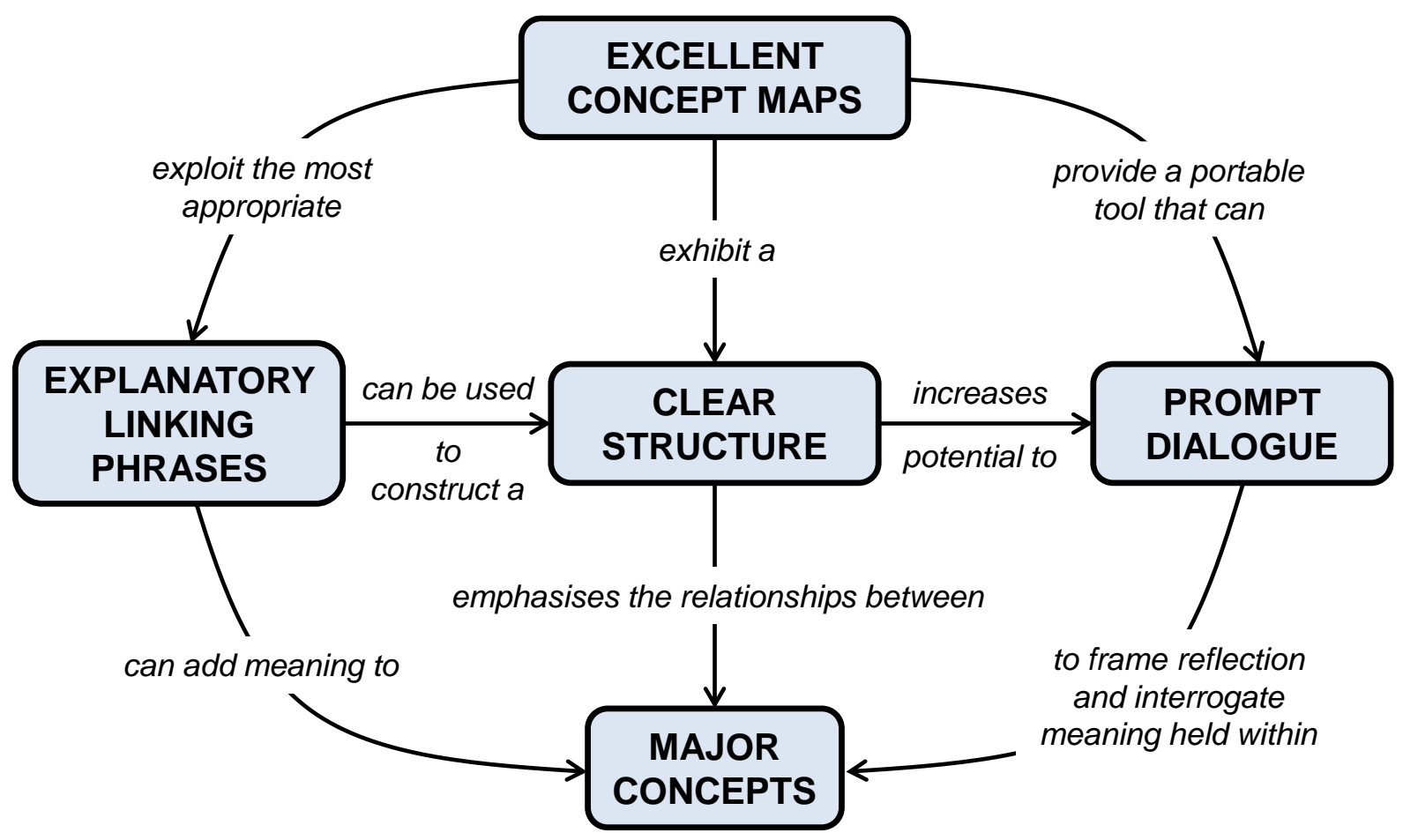

Fig. 2. The characteristics of excellent concept maps, summarised as a concept map

It might be assumed that smaller concept maps take less time to construct than larger maps. This has not been found to be the case. During the map-mediated interviews used to chart the elements of pedagogic frailty (Kinchin et al, 2016), the interviews that have been undertaken to produce these sets of maps have typically each taken about two hours. During the interview the interviewee is often able to identify the concepts they want to include within the map relatively quickly, but then it takes time to arrange and link the concepts in a way that satisfies the interviewee. Some time to reflect on and revise these maps then allows the interviewee to refine the terms used in order to maximize the map's explanatory power.

The intended use of the concept map is to enable dialogue about teaching so that academics might be able to purposefully reflect on their practice. This is within a shared framework that also allows them to engage in dialogue with colleagues from other disciplines. The defining attributes of the model, as explored by individual academics, can be considered on various levels:

- $\quad$ The content of each dimension. Which concepts they include in their maps and which, if any, is seen as the dominant concept. And importantly, which concepts are omitted.

- The structure of each dimension. If concept maps are strongly linear they tend to be indicative of routine expertise, whereas highly integrated networks are 
more likely to indicate a level of adaptive expertise, and more likely to connect with the content of the other dimensions (as is the case with the regulative discourse example in Fig. 1).

- The consistency across dimensions (i.e. whether there is internal conflict within an individual profile - where propositions within one dimension seem to contradict or be in conflict with propositions in other dimensions).

- $\quad$ The level of language that is used - particularly in the linking phrases included in a map. Instances where the same linking phrase is used repeatedly are often indications that the participant has not previously thought deeply about their teaching.

Even when an individual academic possesses a profile that exhibits appropriate content, integrated structure, strong consistency and explanatory language, the important aspect is how that profile fits within the network of other personal profiles within their professional context. If everyone else in the department holds a conflicting sense of the teaching discourse, the research-teaching nexus and the level of regulation, then there is potential for frailty. This may indicate the need to find a balance between 'agency' (where an individual has a strong self-identity and the ability to direct their own professional activity) and 'frailty' (where that individual's views - or the dominant view in the department - conflict with other views in the institution, including peers from other disciplines or centralised management).

The mapping of academic perceptions of the dimensions of frailty is not intended to trace the outcomes against a pre-determined fixed route with which to judge colleagues. There is no intention to label individuals as 'frail'. Indeed, it has been made explicit in the supporting literature that this is not appropriate and that the unit of analysis of frailty lies in the links between academics or groups of academics. Frailty, where it exists, is therefore a quality of the system and not of the individual. But in order to map the system, we need to uncover the beliefs of the individuals that make up the network of views across the institution. The point is to explore the landscape of academia. The concept maps of the dimensions of frailty are open and connectable in all of their dimensions. Elements are detachable, reversible, and susceptible to constant modification. Indeed, it will be seen that the development of academic reflections upon frailty and resilience will map a path that is personal, entangled, non-linear and iterative as the academic explores the multiple landscapes of their personal and professional experience and brings them into relation with each other.

\section{The papers}

The papers collected here vary in their initial focus between pedagogic frailty as an issue and concept mapping as a tool. Fig. 3 presents our attempt to create an overview of this volume, by identifying broad concepts to support the readers' navigation throughout the articles. The "need for improving teaching in higher education" is the particular feature that aligns all contributions. The "Pedagogic Frailty model" (centre) informs how to deal with this challenge, and two complimentary dimensions emerged: emotional (left) and cognitive (right).

Emphasis on emotional dimension expanded authors' discussions about innovation, risk management and faculty development. Indeed, students' reflection about resilience and learning assessment were considered as essential elements embedded into 
the teaching experience. It is worthy to note that the concept "learning assessment" connects both sides of the map.

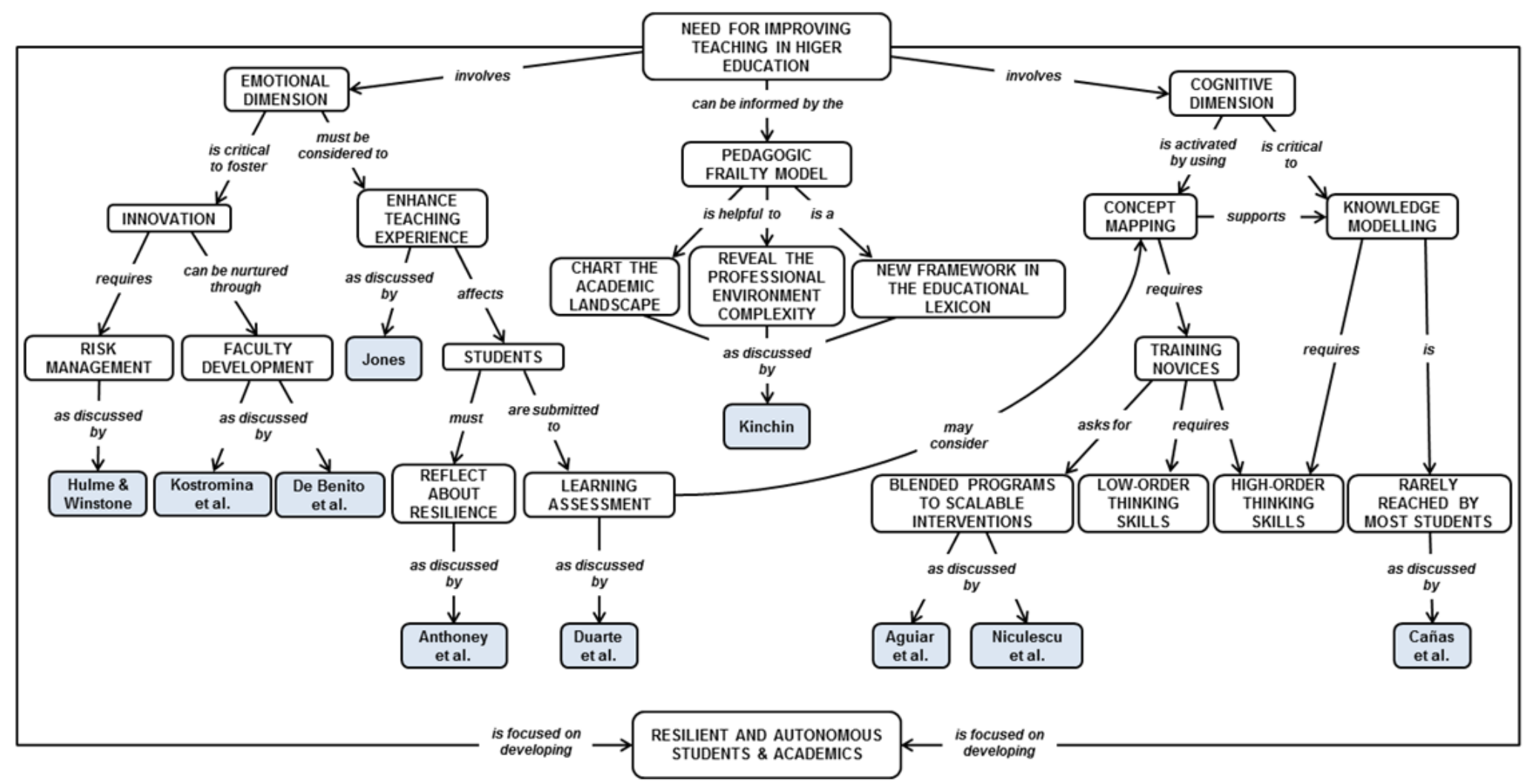

Fig. 3. Overview of this volume as a concept map from the identified dimensions (emotional and cognitive). This concept map addresses the following focus question: how can you explore the articles (blue boxes) of this volume?

The cognitive dimension starts with "concept mapping" and "knowledge modelling", as a way to make visible our thoughts, beliefs, and ideas. The need for training novices and using technology to disseminate the Pedagogic Frailty model was highlighted. The naïve use of concept maps hinders the user to reach high-order thinking skills, which are critical to life-long and self-regulated learning.

The connection between the initial and final concepts is intentionally repeated to highlight that the development of "resilient and autonomous students \& academics" ask for the combination of the emotional and cognitive dimensions. They form a sustainable path to pursue the improvement of teaching in higher education, from the information gathered through the Pedagogic Frailty model.

\section{References}

Kinchin, I. M. (2015). Pedagogic frailty: An initial consideration of aetiology and prognosis. Paper presented at the annual conference of the Society for Research into Higher Education (SRHE). Celtic Manor, Wales. Retrieved from 
https://www.srhe.ac.uk/conference2015/abstracts/0026.pdf

Kinchin, I. M. (2016). Visualising powerful knowledge to develop the expert student: A knowledge structures perspective on teaching and learning at university. Rotterdam: Sense Publishers.

Kinchin, I. M., Alpay, E., Curtis, K., Franklin, J., Rivers, C., \& Winstone, N. E. (2016). Charting the elements of pedagogic frailty. Educational Research, 58(1), 1-23.

Kinchin, I. M., \& Francis, R. A. (2017). Mapping pedagogic frailty in geography education: A framed autoethnographic case study. Journal of Geography in Higher Education, 41(1), 56-74. 